\title{
Preditores da Correspondência Intenção-Compra: Experimento Natural com Reforço das Marcas
}

\author{
Rafael Barreiros Porto ${ }^{1}$ \\ Jorge Mendes de Oliveira-Castro \\ Universidade de Brasília
}

\begin{abstract}
RESUMO - Alguns consumidores entram em lojas dispostos a comprar marcas que conduzem a diferentes reforços utilitários e informativos. Eles podem ou não comprá-las a depender de suas histórias de aprendizagem e dos estímulos de marketing presentes no ambiente de compra. O objetivo deste trabalho foi investigar a predição de ambas variáveis sobre a correspondência intenção-compra comparando grupos de reforços utilitários e informativos das marcas. Foi feito um delineamento experimental natural entre-sujeitos com 1.016 consumidores. Os resultados indicaram que quando as marcas oferecem maiores reforços, os consumidores apresentam maior correspondência entre a intenção e a compra e que a história de aprendizagem foi preditora em todos os grupos experimentais. Esses resultados contribuem empiricamente para a validação do modelo comportamental em consumo.
\end{abstract}

Palavras-chave: comportamento do consumidor, intenção, reforço, escolha de marca, aprendizagem

\section{Predictors of the Intention-Purchase Correspondence: A Natural Experiment with Brand Reinforcement}

\begin{abstract}
Some consumers go into stores willing to buy brands that lead to different utilitarian and informational reinforcement. They may or may not buy them depending on their learning histories and marketing stimuli in the purchase environment. The aim of this study was to investigate the prediction of both variables on the correspondence between intentionpurchase, comparing informational and utilitarian reinforcement groups of brands. A natural between-subjects experiment with 1,016 consumers was realized. The results indicated that when brands offer more reinforcements a higher correspondence between intention and purchase was observed and that the learning history was a predictor in all experimental groups. These results contribute to the empirical validation of the behavioral model in consumption.
\end{abstract}

Keywords: consumer behavior, intention, reinforcement, brand choice, learning

Desde que Klein e Lansing (1955) propuseram uma métrica de probabilidade nas medidas de intenção comportamental, a área de psicologia do consumidor tem utilizado esta variável para predizer o real comportamento de compra (Ajzen, 2008; Bagozzi, 1982). Contudo, a indicação de quais são as variáveis que realmente influenciam a correspondência entre a intenção e a compra (I-C) é escassa na literatura. A importância dos estudos dessa temática é revelar o que faz os indivíduos escolherem ou deixarem de escolher determinadas marcas. Isso tem uma implicação direta para a ciência psicológica, já que demonstra a relação entre o conativo da atitude - intenção - e um comportamento corriqueiro dos indivíduos, compra de produtos. Ao mesmo tempo, há uma implicação nas atividades mercadológicas de cada marca, uma vez que seus gestores elaboram inúmeras atividades com propósito de que uma marca seja comprada em relação às outras concorrentes, alterando as tendências de compra. Logo, revelar o poder preditivo das variáveis que estimulam a correspondência I-C é um meio para evitar desnecessários trabalhos gerenciais e evidenciar o que incentiva os indivíduos fazerem aquilo que eles dizem que irão fazer.

1 Endereço para correspondência: Universidade de Brasília, Programa de Pós-Graduação em Administração - Instituto Central de Ciências, Ala norte, Subsolo, módulo 25. Brasília, DF. CEP 70910-900. E-mail: rafaelporto@unb.br
Pesquisadores em consumo têm utilizado variáveis atitudinais como preditoras do comportamento, tendo como base teorias da cognição social (Fishbein \& Ajzen, 1975), mas encontram baixo poder preditivo da intenção sobre o comportamento (Foxall, 1997). Um problema metodológico que tem sido apontado referente à baixa predição da intenção sobre o comportamento é a falta de rigor experimental dos estudos, sendo a maior parte correlacionais (Sheeran, 2002). Mesmo quando são experimentais, não ocorrem em ambiente natural, ofertando cenários hipotéticos (Webb \& Sheeran, 2006). Ademais, variáveis situacionais que efetivamente estão presentes quando os consumidores têm que executar o comportamento de compra, dentre elas, as estratégias de marketing de cada marca, não são inseridas nas equações dos modelos atitudinais.

Por outro lado, os estudos de marketing geralmente demonstram que o composto mercadológico (ex: preço e propaganda) das marcas estimula ou desestimula indivíduos a comprarem (Ehrenberg, Uncles, \& Goodhardt, 2004), mas ele tem sido pouco relacionado com constructos atitudinais. Os pesquisadores que investigam o papel das estratégias o fazem em relação à compra e não à intenção. Assim, poucos estudos sobre a relação I-C utilizam delineamento experimental em ambiente natural, investigando também as reais variáveis situacionais que podem estimular ou desestimular a correspondência entre ambos, como as estratégias de marketing. 
Um caminho para a solução tem sido apontado por Foxall (1990/2004). Ele sugere que as variáveis individuais do consumidor revelam suas experiências, sua história de aprendizagem. Já os estímulos de marketing fazem parte do cenário de consumo, onde o consumidor pode ou não realizar um comportamento. Ambos são combinados na predição da escolha subsequente. Além disso, ele sugere consequências do comportamento. Uma vez realizado, há consequências utilitárias e informativas das marcas que podem aumentar / diminuir a probabilidade de que algumas sejam adquiridas novamente. Mas pouco se sabe da relação dos consequentes utilitários e informativos na relação I-C.

Este trabalho se baseou nessa problemática e propõe juntar as peças (relação I-C, antecedentes individuais dos consumidores, estratégias de marketing presentes no cenário e consequências reforçadoras das marcas). Apresenta-se uma investigação preditiva das estratégias de marketing das marcas e da história de aprendizagem dos consumidores sobre a correspondência intenção-compra comparando grupos de reforços das marcas. Dois objetivos específicos são propostos: 1) analisar o grau de correspondência entre as intenções e as compras efetivas em grupos que adquiriram diferentes magnitudes de reforçadores utilitários e informativos e 2) analisar a influência preditiva das estratégias de marketing de cada marca e da história de aprendizagem dos consumidores sobre a correspondência intenção-compra com o controle dos reforços utilitários e informativos. Para melhor compreensão são explicitadas algumas críticas dos modelos teóricos concernentes à relação intenção-compra normalmente utilizados nos estudos empíricos, a proposta do uso de um modelo mais comportamental e um teste empírico aplicado a esta relação.

No modelo do comportamento planejado (Ajzen, 1991), o antecedente imediato do comportamento é a intenção de comportar-se perante um objeto ou situação. Intenções comportamentais são "instruções que as pessoas dão para si mesmas para se comportarem de certa maneira" (Triandis, 1980, p. 203). Podem ser inferidas de respostas verbais tais como: "eu pretendo fazer X", "eu planejo fazer X" ou "eu irei fazer X". A intenção indexa a motivação para realizar comportamento e abrange tanto a direção (fazer $\mathrm{X}$ ou não fazer $\mathrm{X}$ ) e a intensidade (o quanto de esforço a pessoa terá de despender) em uma decisão. Para verbalizar o "querer realizar", mede-se a intenção com uso de uma escala dicotômica (irei realizar / não irei realizar) ou intervalar (por exemplo: probabilidade de realização). Muitas vezes essas medidas são utilizadas como substitutas (proxies) do próprio comportamento real.

Esse modelo tem sido insuficiente, contudo, para prever comportamento real, em específico, o de escolha de compra de marcas. Ele ignora os comportamentos anteriores do indivíduo (Bagozzi, 1982; Foxall, 1997), não incluem a quantidade de informações durante a formação da intenção (Pieters \& Verplanken, 1995); ignoram a importância pessoal e situacional do sujeito com o objeto de atitude (Chaiken, Wood, \& Eagly, 1996; Petty, 1995), ignoram o tamanho e o conteúdo do ambiente do comportamento (Foxall, 1997), os recursos e a cooperação (Liska, 1984), dentre outros. A ausência desses itens leva à baixa correspondência entre intenção e comportamento.
Há outros modelos que agregam alguns desses itens e propõem menor esforço cognitivo, tais como o modelo de probabilidade de elaboração (Petty, 1995) e o modelo de composição (Chaiken et al., 1996). Neles, além do processo sistemático cognitivo, similar ao modelo do comportamento planejado, o comportamento pode ser predito por afetos desprovidos de cognição ou por processo heurístico que é salientado no momento da decisão. Partem de análise de efeitos de condicionamento clássico ou de efeitos de julgamento heurístico que vêm de auto-observação em situações anteriores.

Esses últimos modelos solucionam parte da crítica de predição ao inserir a capacidade de processamento pelos indivíduos (tanto capacidade situacional - distração - quanto capacidade individual - inteligência geral), os fatores de relevância do objeto e aqueles referentes à relevância da situação em que se encontra o indivíduo (envolvimento). Porém, outras críticas ainda persistem, tais como: ausência da relação com comportamentos anteriores, ausência de características da formação da intenção e ausência da característica do ambiente na situação de compra. Assim, ao inserir todas as variáveis dos modelos existentes e acrescentar tantas outras, a construção de novos modelos que expliquem a compra torna-se mais complexa e menos parcimoniosa. Para evitar esse estado, duas amplas linhas de pesquisa chamadas, "consistência intenção- comportamento" e "perspectivas comportamentais em consumo" têm impulsionado e direcionado os esforços para uma direção mais direta, evitando desvios do foco central.

Na meta-análise da consistência intenção-comportamento de Sheeran (2002) foram achadas 10 metas-análise sobre essa relação. Seu resultado apontou que apenas $28 \%$ da variância explicada do comportamento se devem à utilização da intenção para prever o comportamento subsequente. Ademais, a intenção comportamental normalmente é contraposta ao comportamento passado. Ouelette e Wood (1998) fizeram uma meta-análise sobre hábitos (repetição do mesmo comportamento emitido) e intenções. Eles demonstram que, em contextos estáveis, comportamento passado prediz melhor comportamento futuro. Em compensação, em contextos instáveis, intenções são melhores preditoras do comportamento futuro. Assim, investigar a emissão do comportamento (anterior e verbal que demonstre intenções comportamentais) e a estabilidade ou não do contexto parecem ser necessários na explicação da predição intenção-compra, evitando desvios da explicação.

Na perspectiva comportamental, Foxall (1997) já sugeria isso. Ele propôs um modelo capaz de abarcar o comportamento passado e as intenções dos consumidores levando em consideração as situações (contextos) de escolha, em especial de escolha de marcas. Foxall (1990/2004) propõe um modelo - modelo da perspectiva comportamental (BPM) - para analisar a situação do consumidor e investigar por que e como consumidores escolhem marcas diferentes (ou similares). No modelo, o comportamento do consumidor é explicado analisando-se antecedentes, cenário onde ocorre o comportamento e a história de aprendizagem do consumidor e consequentes, reforço e punições utilitárias e informativas.

No cenário de comportamento, analisam-se a presença e frequência de estímulos discriminativos que sinalizam a probabilidade de consequências. Esses estímulos podem ser: 
físicos (peças de propaganda dentro da loja, logomarcas), sociais (presença de vendedores ou co-compradores tal como um filho de um comprador), temporais (horários em que a loja fica aberta) e regulatórios (regras tais como "proibido fumar", "proibido abrir embalagens"). A presença de quaisquer desses exemplos sinaliza uma probabilidade de consequência. Esses estímulos discriminativos normalmente vêm acompanhados de vários outros, caracterizando um determinado ambientede compra, de uso etc. As estratégias de marketing das marcas (desconto em preço, peças de propaganda e localização dos produtos nas prateleiras) realizadas pelos varejistas podem estar contidas no cenário, na tentativa de fazer o consumidor escolher uma delas.

$\mathrm{Na}$ história de aprendizagem analisam-se efeitos dos reforços ou punições de comportamentos já realizados pelo individuo em qualquer situação anterior do cenário de consumo. Pode-se analisar se ele já comprou e usou uma marca que teve como consequência a facilidade no uso, seus hábitos ou intenções, taxas de lealdade, tempo poupado, etc. Essa aprendizagem é particular e pode ser capturada ao longo de um período de experiências de consumo, devido a sua exposição em cenários com estimulações físicas, sociais ou regulatórias. Assim, tanto estudos que observam comportamentos em contingências passadas ou estudos sobre comportamentos passados (Ouelette \& Wood, 1998) quanto estudos que analisam relatos de intenção comportamental (Ajzen, 2001; Chaiken et al. 1996; Fishbein \& Ajzen, 1975; Petty, 1995), de processamento de informação (Bettman, Luce, \& Payne, 1998) e lealdade de consumidores (Dick \& Basu, 1994) permitem identificar a história de aprendizagem do consumidor antes dele entrar no cenário de consumo e realizar algum tipo de comportamento. Eles demonstram igualmente, antecedentes do comportamento de compra, porém com foco maior no consumidor do que na situação.

Já os consequentes do comportamento realizado na situação de compra no modelo de Foxall (2002) podem ser utilitários ou informativos e ambos podem ser reforçadores ou punitivos sobre o comportamento realizado. Consequências utilitárias são resultados técnicos da compra e uso de produtos e serviços. Derivam do manuseio do produto ou do exercício do serviço. São consequências materiais ou pragmáticas da aquisição, posse, uso e consumo como um todo. Conforto, itens limpos, saciação da fome são obtidos apenas caso o produto ou serviço seja usado. Eles podem ser reforçadores ou punitivos. Se eles aumentarem ou mantiverem o comportamento serão reforçadores. Se eles diminuírem, serão punitivos.

Consequências informativas são simbólicas e derivam das ações e reações no relacionamento social (Foxall, 1990/2004). Consistem em feedback social da performance do indivíduo enquanto consumidor. Ou seja, são consequências que só têm como ser obtidas caso sejam mediadas por uma pessoa ou grupos de pessoas. Essas consequências podem ser status, prestígio, realização ou respeito. Igualmente, eles podem ser reforçadores ou punitivos (Foxall, 1990/2004). Os produtos e serviços de consumo são concebidos como consequentes em eixos ortogonais, ou seja, um determinado produto pode ter graus de utilitário e graus de informativo ao mesmo tempo. Portanto, níveis de consequentes utilitários e informativos podem ser utilizados.
Ao abarcar a longa lista de antecedentes do comportamento de compra colocando todas as variáveis atitudinais ou de outros tipos que já ocorreram, ou como histórico de aprendizagem ou como cenário de compra, permite-se adquirir mais parcimônia na explicação, sem, no entanto, desconsiderá-las. Ademais, esse modelo acrescenta as consequências do ato de compra que podem influenciar emissões de comportamentos subsequentes. Entretanto, não se tem utilizado esse modelo para (1) explicar correspondências ou a falta de correspondência entre intenção-compra, (2) a magnitude dos reforços adquiridos, caso o consumidor apresente correspondência I-C, (3) os antecedentes desse tipo de correspondência levando em consideração as consequências que as marcas podem propiciar ao consumidor. $\mathrm{O}$ presente estudo pretende abrir caminhos para uso desse modelo mais parcimonioso, unindo a área de comportamento do consumidor e marketing.

\section{Método}

\section{Delineamento}

Esta pesquisa utilizou delineamento experimental em ambiente natural, entre-sujeitos, com quatro grupos experimentais. Um modelo (Figura 1) foi elaborado baseado no modelo BPM (Foxall, 1990/2004) com adaptações para representar as variáveis empiricamente investigadas neste trabalho.

\section{Participantes}

Ao longo de nove semanas seguidas, uma amostra aleatória de 1.016 participantes que entraram em uma grande loja de departamento de desconto no Brasil foi selecionada. A aleatoriedade da amostra foi estabelecida por meio de randomização dos tipos de perguntas contidas na abordagem inicial junto aos consumidores. Para cada consumidor que se aproximasse da entrada da loja, aplicava-se questionário sobre um dos quatro produtos foco da pesquisa que ele pretenderia comprar naquele local. $\mathrm{Na}$ saída observou-se a compra de todas as marcas de quatro produtos (caixa de bombom, hidratante de corpo, tintura de cabelo ou barra de cereal), caso ele tenha comprado.

Se o participante respondesse que pretendia adquirir naquela loja um desses produtos, ele poderia se qualificar para o grupo experimental ou grupo controle. No grupo experimental ele respondeu todas as perguntas do ques-

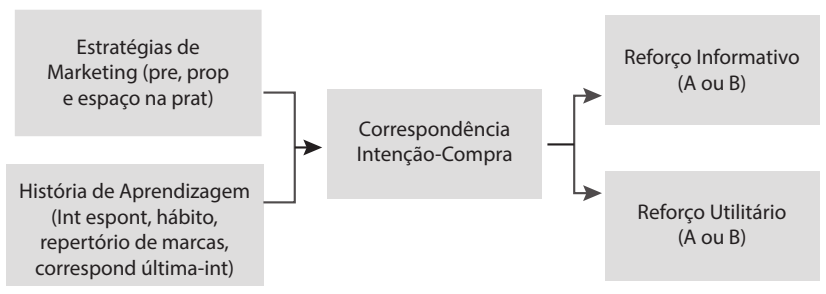

Figura 1. Modelo de Correspondência Intenção-Compra. 
tionário que se referia às intenções de compra da marca e foi abordado na saída para verificação das marcas (e quantidade) que havera comprado. Caso ele participasse do grupo controle, ele não respondia às perguntas sobre marcas e teria apenas as marcas (e quantidade) observadas na saída. O grupo controle fez-se necessário para averiguar se a resposta ao questionário sobre as marcas influenciaria o comportamento de compra. Como não houve diferença significativa entre o grupo com aplicação questionário e sem aplicação $\left(\chi^{2}=0,73 ; \mathrm{p}>0,05\right)$, priorizou-se relatar apenas os resultados dos grupos experimentais (com questionários, foco do trabalho). Em cada grupo experimental havia consumidores que compraram marcas que propiciaram reforços utilitários (alto ou baixo) e informativos (alto ou baixo).

Do total, apenas 461 participantes $(45,4 \%)$ efetivamente compraram alguma marca dentro da loja e compuseram a amostra definitiva do estudo. Geralmente eram do gênero feminino (89\%), com renda familiar mensal mediana de R\$ $1.001,00$ a $\mathrm{R} \$ 2.000,00$ e não estavam acompanhados de outro consumidor $(65 \%)$.

Ao todo, eles poderiam escolher 63 marcas, sendo 10 de caixa de bombom, 12 de barra de cereal, 14 de hidratante e 27 de tintura de cabelo. Essas marcas são de produtos com alta frequência de compra - pelo menos uma vez ao mês os consumidores os compram - e que estavam disponíveis na loja. Ressalta-se que os produtos são de alta frequência, mas as marcas não necessariamente eram. Algumas são compradas diariamente outras não, podendo ficar estocadas nas gôndolas.

\section{Procedimentos}

Para comparar as intenções de compra com o comportamento de compra do mesmo participante foi planejado na fase piloto que cada consumidor teria um código (com números e cores diferentes), assim que terminasse de responder o questionário na entrada da loja. Dessa forma, ao final da aplicação do questionário, foi entregue uma (ou mais) ficha(s) com quatro cores diferentes - um para cada produto que relatou que iria comprar. Cada ficha continha um número identificador do consumidor em cada dia da coleta. Quando o consumidor saísse da loja, foi abordado por auxiliares de pesquisa que recolheram as fichas e solicitaram a apresentação visual do produto, marca, tipo e quantidade comprada.

Para aumentar a quantidade de consumidores que seriam abordados por dia foi condicionada a entrega de brindes. Assim, após o consumidor ter respondido o questionário na entrada da loja e do auxiliar entregar a(s) ficha(s), era dada a instrução de como receber o brinde. Especificamente, se ele entregasse a ficha na saída para a equipe de auxiliares, poderia escolher um brinde - uma bola de plástico, um brinco dourado ou um bombom. Ressalta-se que o brinde não estava condicionado à compra ou não do produto ou marca, mas sim à entrega da ficha aos auxiliares da pesquisa na saída da loja. Esta instrução foi dada assim que ele recebia a ficha na entrada da loja. Finalmente, para complementar, uma auxiliar de pesquisa fez o trabalho de auditoria das estratégias de marketing realizadas pelos varejistas para as marcas. Durante todo o dia de coleta de dados, observaram-se e anotaram-se as estratégias em formulário e posteriormente foram transcritas para uma planilha eletrônica.

\section{Instrumentos}

A medida de compra da marca foi baseada em observação da sacola de compra do consumidor na saída da loja pela equipe de auxiliares de pesquisa. Foram observados e anotados no formulário: a marca, o tipo da marca e a quantidade comprada, bem como se era um novo usuário da marca comprada (verbalização da primeira vez que adquiria a marca - dicotômica). Essa última questão foi renomeada para representar se o consumidor era um novo comprador da marca ou se era comprador do repertório de marcas anteriormente comprado.

O questionário, na abordagem inicial, continha medidas de intenção espontânea da marca (solicitava-se oralmente ao sujeito, sem identificação prévia, que marca ele pretendia comprar dentro da categoria do produto. Sua resposta vinha em formato aberto). Esse item foi codificado em escala nominal. Em seguida, solicitava-se a medida de intenção estimulada de compra da marca (com cartão que ilustrava as logomarcas), medida da última marca comprada dos produtos analisados (com uso novamente do cartão) e se a pessoa costumava comprá-la (dicotômica). Essa última questão foi renomeada de hábito de compra da marca. Houve o cuidado para que cada pergunta contextualizasse o comportamento que estava sendo solicitado. Ou seja, cada enunciado da pergunta estimula o consumidor a relatar o contexto da intenção ou da última marca comprada. O enunciado da pergunta de intenção estimulada solicitava: "Desta lista de marcas entregue, relate qual ou quais marca(s) que você pretende comprar (ou adquiriu) no dia de hoje (em sua última compra) nesta loja. Qual o tipo? E em que quantidade?".

As estratégias de marketing de cada marca realizadas pelo varejista também foram monitoradas em cada dia que houve coleta de dados. Foram registrados: o preço de venda de cada marca e seus subtipos, o peso e a quantidade da embalagem, se a marca fora anunciada na revista da loja (dicotômica) e o tamanho em centímetros do espaço ocupado na prateleira.

Para o registro dos reforços utilitários houve o monitoramento da disponibilidade de cada marca na prateleira e observação do conteúdo da embalagem ou do produto com informações técnicas descritas pelo fabricante. Após a coleta, houve a sistematização dos tipos e variedades das marcas dos produtos para classificá-las em níveis de reforço utilitário de acordo com o método utilizado por Foxall, Oliveira-Castro e Schrezenmaier (2004) - adaptado para os produtos selecionados da pesquisa. As marcas foram classificadas em dois níveis, a saber: (1) nível baixo - reforço utilitário que contém o tipo básico, sem diferencial das marcas e com poucos atributos e (2) nível alto - reforço utilitário que contém o tipo avançado - com diferencial - das marcas e com muitos atributos.

Para os reforços informativos, utilizou-se o instrumento utilizado por Pohl e Oliveira-Castro (2008), adaptado para 
os produtos e marcas analisados neste trabalho. Esse é um questionário contendo a lista de todas as marcas existentes dos produtos analisados e campo de resposta para serem preenchidos pelos consumidores perguntando o grau de conhecimento e de percepção de qualidade de cada marca, ambos em escala ordinal. $\mathrm{O}$ nível informativo foi medido em escalas de 0 a 3 para avaliar o grau de conhecimento das marcas, $(0$ - desconhecida a 3 - muito conhecida) e o grau de qualidade percebida $(0$ - sem opinião sobre a qualidade a 3 - alta qualidade). Se o consumidor marcasse 0 na qualidade percebida, ele não era incluído na amostra. Foi calculada a mediana dessas duas medidas para obter o efeito composto, já que "marcas muito conhecidas e percebidas com pouca qualidade" não é igual à "marcas muito conhecidas percebidas com alta qualidade". Em seguida, foram calculadas as médias dessas avaliações agregadas por marca com 95\% de intervalo de confiança. Com isso, estabeleceu-se um ranking dos reforços informativos das marcas.

Posteriormente, foi realizado um teste para verificar a classificação das marcas nos dois níveis informativos: 1) nível informativo baixo - com marcas pouco conhecidas e percebidas com baixa qualidade - e 2) nível informativo alto - com marcas muito conhecidas e percebidas com alta qualidade. Foi utilizada a análise de variância com as marcas de cada produto como variáveis independentes e as médias da marca como variáveis dependentes. Utilizou-se Post Hoc Turkey B de igual variância assumida e os resultados indicaram que as relações entre as marcas e as suas médias das avaliações do conhecimento e qualidade percebida se diferenciam $(\mathrm{p} \leq$ $0,01)$ para todos os produtos analisados: $\mathrm{F}(13,543)=33,38$ com $\eta^{2}=43,5 \%$ para marcas de hidratante, $F(26,1080)=$ 23,98 com $\eta^{2}=36,6 \%$ para marcas de tintura de cabelo, $F$ $(11,468)=58,03$ com $\eta^{2}=57,7 \%$ para marcas de barra de cereal e $F(10,429)=46,83 \operatorname{com} \eta^{2}=52,2 \%$ para marcas de caixa de bombom.

Foi realizada uma análise complementar para se chegar aos dois níveis informativos. Após o teste da análise de variância, cruzaram-se suas médias com as fatias de mercado - fatia de mercado é a soma da quantidade total vendida da marca dividida pela quantidade total vendida do produto (Ehrenberg et al., 2004) -, fazendo com que as classificações dos níveis informativos fossem adaptadas para a amostra dos estímulos observados. Ou seja, as médias foram relacionadas às fatias para adequar o tamanho da amostra dos níveis informativos baixos e altos, já que poderia haver poucas marcas compradas ou para um nível ou para outro. Logo, quando um dos níveis ficou próximo a 50\% (do total comprado) houve o corte dos níveis. Dessa forma, o nível informativo baixo representa as marcas menos conhecidas e/ou percebidas com baixa qualidade que, ao todo, representa cerca de $50 \%$ das compras totais, e o restante representa as marcas de nível informativo alto.

\section{Análise de dados}

Neste estudo, a variável dependente, correspondência intenção-compra em escolha de marcas, é dicotômica (consumidor comprou marca diferente da intencionada $=0$ e consumidor comprou a marca intencionada $=1$ ). Já as variáveis independentes subdividiam-se em estratégias de marketing e história de aprendizagem. As estratégias de marketing das marcas realizadas pelo varejista foram: 1) preço relativo da marca comprada - preço da marca comprada no dia $\mathrm{X}$ dividido pelo preço médio da própria marca nos 26 dias totais, 2) espaço na prateleira - espaço ocupado na prateleira da marca comprada no dia $\mathrm{X}$ dividido pelo espaço ocupado na prateleira média da própria marca nos 26 dias totais e 3) presença ou ausência de anúncio da marca comprada. As variáveis que compuseram a história de aprendizagem foram: 4) intenção espontânea - declaração da intenção espontânea de compra da marca (sim ou não), 5) correspondência entre a última marca comprada e a marca da intenção (sim ou não), 6) hábito de compra da marca (referência: última marca comprada) - costuma ou não comprar a marca da última compra, 7) comprador do repertório de marcas anteriormente comprado - se é novo comprador da marca ou comprador do repertório de marcas já compradas anteriormente. Os grupos foram separados em amostras com o efeito comparativo. Os quatro grupos combinavam os reforços das marcas: baixo utilitário e informativo, baixo utilitário e alto informativo, alto utilitário e baixo informativo e alto utilitário e informativo.

Para identificar o grau das correspondências entre as intenções e as compras efetivas dos grupos experimentais (objetivo específico 1) foi feita uma tabulação cruzada $(2 \times 2)$. Cruzaram-se a quantidade de consumidores que apresentaram correspondência Intenção-Compra e o nível de reforço utilitário (alto ou baixo) e informativo (alto ou baixo) da marca comprada por esses consumidores. O indicador Cramer's V foi utilizado devido às variáveis apresentarem escala nominal. $O$ resultado da quantidade de consumidores que apresentam comportamento correspondente (ou não) e que compraram marcas com reforços diferentes foi utilizado para a análise da predição (objetivo específico 2).

Foram realizadas quatro análises de regressão logística em bloco com o fim de cobrir o objetivo específico 2. Essa análise permite averiguar o efeito de variáveis independentes de qualquer distribuição com uma variável dependente dicotômica (correspondência ou ausência de correspondência) e oferece resultado de probabilidade de que um evento ocorra por meio de uma curva logística. Neste caso, a probabilidade que um consumidor apresente comportamento correspondente à intenção. Fez-se uso de blocos para averiguar se o antecedente, história de aprendizagem, sobrepõe o cenário de consumo, representado pelas estratégias de marketing. No Bloco 1 foram inseridas três estratégias de marketing de cada marca realizada pelo varejista e no Bloco 2 foram inseridas quatro variáveis da história de aprendizagem. Análise da ROC Curve foram complementares com o fim de ter a representação geral dos resultados. Ela forneceu indicações da probabilidade predita de correspondência I-C para cada bloco. Quanto maior a área abaixo da linha, maior a probabilidade predita.

O poder amostral da regressão logística, post hoc, bicaudal, probabilidade de erro $\alpha$ a 0,05 , com tamanho amostral de 461 participantes apresentou-se igual a 0,98 , com Z Crítico na ordem de 1,96 . Isso significa que o tamanho amostral para o teste utilizado nesta pesquisa foi suficiente para ter boa garantia de evitação do Erro Tipo 2. 


\section{Resultados}

Inicialmente os resultados dos percentuais da quantidade de participantes que apresentaram correspondência entre a intenção e o comportamento de compra com a magnitude dos níveis informativo e utilitário das marcas são relatados. Posteriormente, exibe-se os resultados referentes à análise de predição em bloco das estratégias (Bloco 1) e a anterior mais a história de aprendizagem (Bloco 2).

Os percentuais de participantes que apresentam correspondência são maiores quando há alta magnitude do nível utilitário e informativo das marcas $(41,5 \%)$ em relação aos outros três grupos experimentais - baixa magnitude do nível utilitário e informativo (19,4\%), baixa magnitude do nível utilitário e alto informativo $(23,7 \%)$ e alta magnitude do nível utilitário e baixo informativo (15,4\%). Assim, marcas mais conhecidas, percebidas com alta qualidade, com muitos atributos e com mais diferenciais são mais prováveis de terem consumidores que apresentam intenções correspondentes ao comportamento. O indicador Cramer's $V$ apresentou valor $=0,2$ com $p \leq 0,01$. Isso significa que a diferença percentual entre os grupos foi estatisticamente significativa, maior do que seria esperada se fosse uma relação aleatória.

Os resultados de predição das estratégias de marketing e da história de aprendizagem sobre a correspondência I-C comprovam que quando é inserida esta última, aumenta-se o $\mathrm{R}^{2}$ Nagelkerke, bem como, o percentual corretamente predito do modelo (Tabela 1).

$\mathrm{Na}$ Tabela 1 é possível averiguar quais variáveis foram preditoras da correspondência I-C e a força da relação [Exp (B)]. Pode se perceber que apenas a variável "anúncio" foi preditora da correspondência I-C quando há reforços utilitários e informativos altos ( $\operatorname{Exp} B=2,77 ; \mathrm{p} \leq 0,05)$ ou quando os reforços utilitários são altos e os informativos baixo ( $\operatorname{Exp} \mathrm{B}=3,97 ; \mathrm{p} \leq 0,05)$. Ou seja, os anúncios são funcionais para estimular a correspondência I-C nessas situações. Contudo, essa estratégia deixa de ser preditora da correspondência I-C quando são inseridas as histórias de aprendizagem com a marca.

A variável "correspondência entre a última marca comprada e a marca da intenção" foi preditora positiva da variável dependente em todos os grupos experimentais $(\operatorname{Exp} \mathrm{B}=5,10$ com $\mathrm{p} \leq 0,01 ; \operatorname{Exp} \mathrm{B}=5,48$ com $\mathrm{p} \leq 0,01 ; \operatorname{Exp} \mathrm{B}=6,76$ $\operatorname{com} p \leq 0,01 ; \operatorname{Exp} B=4,57$ com $p \leq 0,01$ ). Isto sugere que quanto mais o consumidor declara intenção de comprar a marca que ele comprou da última vez, maior a probabilidade de ele apresentar comportamento de compra subsequente correspondente ao da sua intenção, quaisquer que sejam as magnitudes de reforço das marcas. Altera-se apenas a força da relação, sendo maior para o grupo de nível utilitário alto e informativo baixo.

A variável "ser comprador do repertório de marcas anteriormente comprado" também foi preditora positiva da relação I-C, no grupo experimental com nível de reforço utilitário e informativo baixo (Exp $\mathrm{B}=17,2 ; \mathrm{p} \leq 0,01)$ e com nível de reforço utilitário alto e informativo baixo (Exp $\mathrm{B}=37,1 ; \mathrm{p} \leq 0,01)$. Ou seja, quanto mais o consumidor compra marcas dentro de seu repertório habitual, maior a probabilidade de ele apresentar comportamento de compra de marcas correspondente ao da sua intenção que tragam baixo reforço informativo.
A variável "intenção de compra espontânea" foi preditora positiva da correspondência I-C apenas no grupo experimental com marcas de nível utilitário e informativo alto (Exp $\mathrm{B}=3,67 ; \mathrm{p} \leq 0,01)$. Ou seja, quando o consumidor declara espontaneamente sua intenção de compra da marca aumenta-se a probabilidade de ele apresentar correspondência I-C subsequente, contudo apenas no grupo experimental com marcas que propiciam maiores reforços, tanto utilitário quanto informativo. Chama-se atenção que as variáveis "hábito de compra da marca", "preço relativo" e "espaço na prateleira" não foram preditoras da correspondência I-C.

Além disso, para cada grupo experimental, foi calculada a probabilidade de o indivíduo apresentar a correspondência intenção-compra, caso ele demonstre o padrão de história de aprendizagem de acordo com o peso das variáveis significativas de cada grupo no Bloco 2 da regressão logística. Essa probabilidade foi calculada seguindo a fórmula: $\mathrm{P}(\mathrm{X})=1 / 1+\mathrm{e}^{-(\alpha+\Sigma \beta X)}$.

Para o grupo experimental de reforços utilitário e informativo baixo, se o indivíduo tem a história de ter apresentado "correspondência entre a última marca comprada e a marca da intenção" e também "ser comprador do repertório de marcas anteriormente já comprado", a probabilidade de ele apresentar correspondência intenção-compra é igual a 95,8\%. Para o grupo experimental de reforço utilitário baixo e informativo alto, se o indivíduo tem a história de ter apresentado "correspondência entre a última marca comprada e a marca da intenção", a probabilidade de ele apresentar correspondência intenção-compra é igual a 39,4\%.

Já para o grupo experimental de reforços utilitário alto e informativo baixo, se o indivíduo tem a história de ter apresentado "correspondência entre a última marca comprada e a marca da intenção" e também "ser comprador do repertório de marcas anteriormente já comprado", a probabilidade de ele apresentar correspondência intenção-compra é igual a $99,9 \%$. E, finalmente, para o grupo experimental de reforços utilitário e informativo alto, se o indivíduo tem a história de ter apresentado "correspondência entre a última marca comprada e a marca da intenção" e também "declarar intenção de compra espontânea", a probabilidade de ele apresentar correspondência intenção-compra é igual a 82,03\%.

A curva ROC (Figura 2) indica que com ambos os blocos de variáveis há $81 \%$ da área debaixo da curva $(\mathrm{p} \leq 0,01)$. Como um todo, o resultado sugere que a história de aprendizagem é mais importante de ser analisada para predizer se a intenção dos consumidores realmente vai se concretizar do que as estratégias de marketing, especialmente quando há maiores níveis de reforço utilitários ou informativos, sem desprezar a influência das estratégias das marcas.

\section{Discussão}

Os resultados forneceram caminhos para investigar a relação intenção-compra e torna evidente que as variáveis da história de aprendizagem do consumidor com as marcas são suas preditoras mais fortes. Isso quer dizer que quanto mais o consumidor tiver contato anterior com as marcas, maior a probabilidade de ele apresentar intenção correspondente à sua compra para todos os grupos de reforços de marcas. Esse 
Tabela 1. Preditores da correspondência intenção-compra com níveis de reforço.

\begin{tabular}{|c|c|c|c|c|c|c|c|c|}
\hline $\begin{array}{l}\text { Nível } \\
\text { Util. }\end{array}$ & $\begin{array}{l}\text { Nível } \\
\text { Inf. }\end{array}$ & B1. & $\begin{array}{c}\% \mathrm{R}^{2} \\
\text { Nagelkerke }\end{array}$ & $\begin{array}{l}\% \text { corret. } \\
\text { predito }\end{array}$ & Variáveis independentes & $\mathrm{B}$ & E. P & $\operatorname{Exp}(B)$ \\
\hline \multirow{11}{*}{ Baixo } & \multirow{11}{*}{ Baixo } & \multirow{3}{*}{1} & \multirow{3}{*}{4,2} & \multirow{3}{*}{59,7} & Anúncio & $-0,31$ & 1,3 & 0,7 \\
\hline & & & & & Preço relativo & $-0,94$ & 0,9 & 0,4 \\
\hline & & & & & Espaço na prateleira & $-0,01$ & 0,1 & 0,9 \\
\hline & & \multirow{7}{*}{2} & \multirow{7}{*}{25,5} & \multirow{7}{*}{72,7} & Anúncio & 0,01 & 1,4 & 1,0 \\
\hline & & & & & Preço relativo & 0,09 & 1,1 & 1,1 \\
\hline & & & & & Espaço na prateleira & $-0,10$ & 0,1 & 0,9 \\
\hline & & & & & Corresp. última compra e intenção** & 1,63 & 0,7 & 5,1 \\
\hline & & & & & Intenção espontânea & 0,82 & 0,7 & 2,3 \\
\hline & & & & & Hábito de compra & 0,36 & 0,8 & 1,4 \\
\hline & & & & & Comprador do repertório de marca** & 2,85 & 1,2 & 17,2 \\
\hline & & & & & Constante & $-1,36$ & 1,8 & 0,3 \\
\hline \multirow{11}{*}{ Baixo } & \multirow{11}{*}{ Alto } & \multirow{3}{*}{1} & \multirow{3}{*}{9,6} & \multirow{3}{*}{74,1} & Anúncio & 1,75 & 1,1 & 5,8 \\
\hline & & & & & Preço relativo & 0,96 & 1,1 & 2,6 \\
\hline & & & & & Espaço na prateleira & $-0,26$ & 0,2 & 0,8 \\
\hline & & \multirow{7}{*}{2} & \multirow{7}{*}{34,1} & \multirow{7}{*}{81,5} & Anúncio & 1,83 & 1,2 & 6,3 \\
\hline & & & & & Preço relativo & 2,00 & 1,7 & 7,4 \\
\hline & & & & & Espaço na prateleira & $-0,31$ & 0,2 & 0,7 \\
\hline & & & & & Corresp. última compra e intenção** & 1,70 & 0,6 & 5,5 \\
\hline & & & & & Intenção espontânea & $-1,10$ & 0,9 & 0,3 \\
\hline & & & & & Hábito de compra & 1,58 & 0,9 & 4,9 \\
\hline & & & & & Comprador do repertório de marca & $-18,90$ & 40,9 & 0,0 \\
\hline & & & & & Constante & $-2,13$ & 2,0 & 0,1 \\
\hline \multirow{11}{*}{ Alto } & \multirow{11}{*}{ Baixo } & \multirow{3}{*}{1} & \multirow{3}{*}{15,5} & \multirow{3}{*}{72,3} & Anúncio* & 1,38 & 0,8 & 4,0 \\
\hline & & & & & Preço relativo & $-2,78$ & 2,7 & 0,1 \\
\hline & & & & & Espaço na prateleira & $-0,14$ & 0,3 & 0,9 \\
\hline & & \multirow{7}{*}{2} & & & Anúncio & 1,31 & 0,8 & 3,7 \\
\hline & & & & & Preço relativo & $-4,22$ & 3,3 & 0,0 \\
\hline & & & & & Espaço na prateleira & $-0,13$ & 0,4 & 0,9 \\
\hline & & & & & Corresp. última compra e intenção** & 1,91 & 0,7 & 6,8 \\
\hline & & & 500 & 754 & Intenção espontânea & 0,45 & 0,7 & 1,6 \\
\hline & & & 50,8 & 15,4 & Hábito de compra & $-1,20$ & 0,8 & 0,3 \\
\hline & & & & & Comprador do repertório de marca** & 3,64 & 1,4 & 37,9 \\
\hline & & & & & Constante & 4,08 & 3,2 & 59,0 \\
\hline & & & & & Anúncio* & 0,57 & 0,6 & 2,8 \\
\hline & & 1 & 5,0 & 74,3 & Preço relativo & 0,46 & 0,6 & 1,6 \\
\hline & & & & & Espaço na prateleira & $-0,07$ & 0,1 & 0,9 \\
\hline & & & & & Anúncio & 0,57 & 0,6 & 1,7 \\
\hline & & & & & Preço relativo & 0,32 & 0,6 & 1,4 \\
\hline Alto & Alto & & & & Espaço na prateleira & 0,01 & 0,2 & 1,0 \\
\hline & & 2 & & & Corresp. última compra e intenção** & 1,52 & 0,4 & 4,6 \\
\hline & & & 274 & 750 & Intenção espontânea** & 1,30 & 0,5 & 3,7 \\
\hline & & & 21,4 & 15,0 & Hábito de compra & 0,30 & 0,5 & 1,4 \\
\hline & & & & & Comprador do repertório de marca & 0,87 & 0,8 & 2,4 \\
\hline & & & & & Constante & $-1,30$ & 0,8 & 0,3 \\
\hline
\end{tabular}




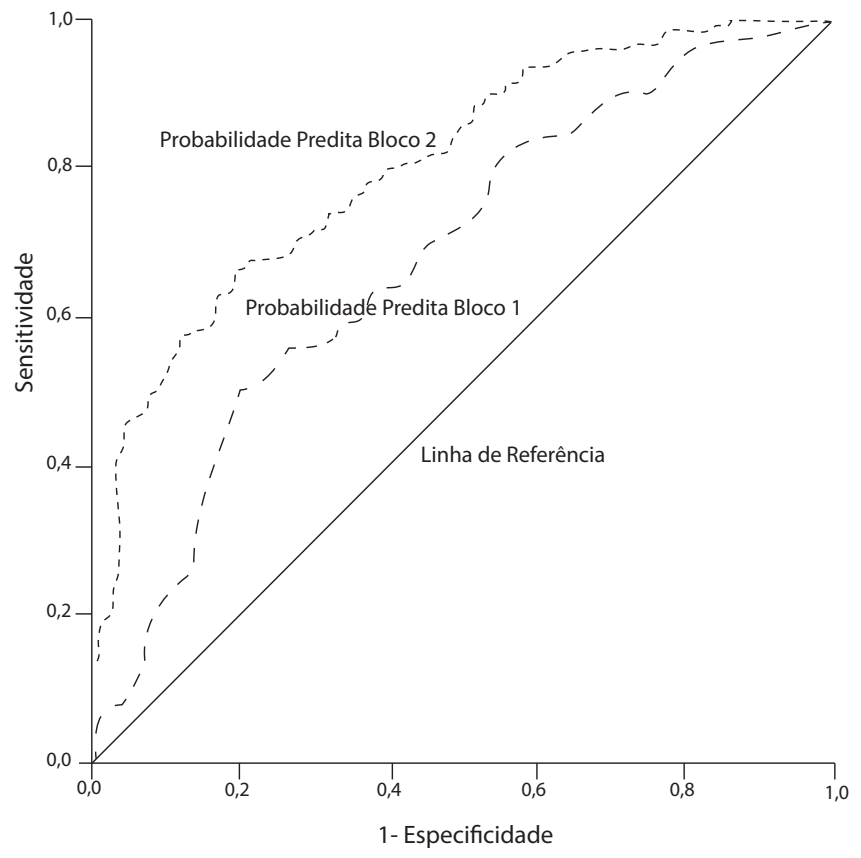

Figura 2. Probabilidades preditas dos Blocos 1 e 2 da Curva ROC

achado contribui com o modelo BPM de Foxall (1990/2004) evidenciando a força da predição dos antecedentes.

Ao encontrar evidências empíricas dessa predição, a explicação comportamental vinda desse modelo pode deixar clara uma discussão clássica na área de consumo: quais são as circunstâncias em que as intenções da marca correspondem às compras. Este trabalho trouxe luz a esta discussão: 1) o consumidor tem que apresentar previamente repertório de compra de marcas que conduzam a baixo reforço informativo dentro da categoria, 2) o consumidor tem que apresentar correspondência entre a última marca comprada e a marca que declara intenção, quaisquer que sejam as magnitudes dos reforços das marcas, 3 ) o consumidor tem que declarar espontaneamente a marca de reforço utilitário e informativo alto que pretende adquirir e 4) devem-se expor anúncios de marcas que conduzam a reforços utilitários altos ao consumidor. Esse último tem uma força mais tímida para incentivar a correspondência. Caso uma ou mais dessas circunstâncias ocorram, pode-se confiar mais nas intenções de compra de marcas - as marcas ditas podem ser as que serão efetivamente compradas.

Em termos específicos, o resultado auxilia a explicar os estudos de Uncles Ehrenberg e Hammond (1995). Esses autores encontraram que consumidores geralmente compram dentro de um pequeno repertório de marcas e que os compram de forma indistinta (sem critérios). O presente trabalho sugere que esse padrão de compra está relacionado com a correspondência I-C quando as marcas oferecem baixa magnitude de reforço informativo. Dessa forma, quando as marcas que podem ser escolhidas são pouco conhecidas e percebidas com baixa qualidade, ou seja, propiciarão pouco feedback sobre seu desempenho enquanto consumidor, ele tenderá a declarar intenção e comprar aquelas que geralmente já compra, resistindo à mudança. Caso o consumidor procure variar nesse contex- to de marcas, ele torna sua declaração de intenção pouco confiável. Esse achado contribui igualmente com os estudos de variabilidade comportamental (Abreu-Rodrigues, 2005), auxiliando a explicação, em termos comportamentais, dos motivos de os consumidores, ocasionalmente, aspirarem pela variação de marcas, tornando-os não correspondentes. Consumidores apresentam apenas variação mínima necessária para atender as exigências da contingência em operação. Ou seja, podem variar apenas porque as marcas já experimentadas não trazem reforços diferentes ou mais ilustrativos de seus desempenhos enquanto consumidores. Se os estímulos discriminativos a serem escolhidos no comportamento subsequente não propiciarem isso, ou seja, todos forem similares e com baixa magnitude informativa de reforço, o comportamento apresentado pelo consumidor será de estereotipia, já que pode obter algum reforço, mesmo que seja o mínimo e com o mínimo custo de obtenção.

Outro resultado revelado deste trabalho é que a intenção espontânea, a principal variável de predição dos modelos atitudinais (Ajzen, 2008), prediz o comportamento correspondente apenas quando há alta magnitude de reforço das marcas. Em outros contextos de marcas, ela fica irrelevante. Resultado similar foi achado por Jannarelli (2006). Algumas pesquisas que analisam a relação de modelos atitudinais sobre o comportamento propõe que variáveis do consumidor são mais importantes do que as situacionais (Foxall, 1997). De fato, para incentivar a correspondência I-C, as variáveis do consumidor foram mais importantes do que as situacionais realizadas pelo varejista, mas isso sem anular o efeito das situacionais de reforço da marca, feitas geralmente pelos fabricantes das marcas. Afinal, as que oferecem maiores reforços conseguiram estimular a correspondência com maior intensidade.

Ademais, este trabalho torna evidente que há outras variáveis mais importantes para estimular a correspondência do que a declaração espontânea da intenção, em especial, quando as marcas não oferecem uma alta magnitude de reforço. O princípio de lealdade verdadeira de Dick e Basu (1994) é uma variável pertencente à história de aprendizagem do indivíduo e neste estudo, com a métrica utilizada, foi preditora em contextos de escolha de marcas em todas as combinações de magnitude de reforço, sejam utilitários, sejam informativos. Ou seja, ela foi preditora em mais situações do que as estratégias e do que a própria declaração de intenção espontânea ou comprar dentro do repertório de marcas previamente comprado. Isso pode auxiliar a explicar porque a lealdade sustentável (verdadeira) é geralmente preferida pelos gestores em relação aos outros tipos de lealdade - latente ou falsa (Dick \& Basu, 1994). No entanto, os estudos da área não deixam claro o que faz aumentar esse tipo de lealdade porque geralmente encontram uma baixa variância explicada para a lealdade comportamental (Perillo, 2007) e não investigam situações referentes à compra entre marcas com distintos reforços.

Este trabalho mediu o princípio de lealdade verdadeira e evidencia que a correspondência da última marca comprada com a intenção de comprá-la e, posteriormente, com sua compra é um fenômeno que pode ser mais bem investigado 
no futuro. Ela figura como um padrão de variável preditora em todos os grupos experimentais analisados. Desse modo, se um gestor possuir uma classificação do comportamento do consumidor baseado na lealdade verdadeira, ele pode ficar muito mais confiante de que de fato o consumidor irá adquirir a marca, independente das estratégias de $\mathrm{ma}$ rketing do varejista. Esse achado é importante para toda a literatura de lealdade do consumidor por demonstrar uma maneira simples de medir o princípio da lealdade verdadeira e de seu resultado contundente nos grupos experimentais, variando apenas no grau entre os grupos. Chama-se atenção que no presente estudo esta variável foi usada como independente para prever a próxima compra e não como dependente, uso típico dos estudos de lealdade do consumidor (Perillo, 2007).

Futuras pesquisas poderiam ser realizadas para generalização dos achados deste trabalho com outros produtos ou mesmo serviços, desde que se identifiquem os níveis de reforço das marcas existentes. Em suma, para incentivar a correspondência I-C, o consumidor tem que conhecer algumas marcas da categoria, inclusive as que conduzem a pouco reforço informativo e/ou reconhecer a marca experimentada no local de venda e/ou conseguir declarar as marcas com maiores reforços, sendo que o anúncio pode ser o estímulo de marketing mais eficaz para isso. O modelo BPM prevê que há maior probabilidade de os consumidores adotarem comportamentos que conduzam aos reforçadores com maiores magnitudes. Isso foi corroborado. Os indivíduos apresentam proporções de correspondência entre a intenção e sua compra subsequente distribuídas diferentemente entre os grupos experimentais e quanto mais uma marca proporcionar reforços utilitários e informativos altos, maior a probabilidade de ter declarações de intenção confiáveis. Isto torna importante a inserção dos reforços utilitários e informativos das marcas (Foxall, 1990/2004; Pohl \& Oliveira-Castro, 2008; Porto, 2009) nas análises em consumo, especialmente se o objetivo for predizer a marca que será comprada de determinado consumidor.

\section{Referências}

Abreu-Rodrigues, J. (2005). Variabilidade comportamental. In J. Abreu-Rodrigues \& M. R. Ribeiro (Eds.), Análise do comportamento: Pesquisa, teoria e prática (pp. 189-210). Porto Alegre: Artmed.

Ajzen, I. (1991). The theory of planned behavior. Organizational Behavior and Human Decision Processes, 50, 179-211.

Ajzen, I. (2001). Nature and operation of attitudes. Annual Review of Psychology, 52, 27-58.

Ajzen, I. (2008). Consumer attitudes and behavior. In C. P. Haugtvedt, P. Herr \& F. R. Kardes (Eds.), Handbook of consumer psychology (pp. 525-548). New York: CRC Press.

Bagozzi, R. (1982). A field investigation of causal relations among cognitions, affect, intentions and behavior. Journal of Marketing Research, 19, 562-584.

Bettman, J. R., Luce, M., \& Payne, J. (1998). Constructive consumer choice processes. Journal of Consumer Research, 25(3), 187-217.
Chaiken, S., Wood, W., \& Eagly, A.H. (1996). Principles of persuasion. In E. T. Higgins, \& A. H. Kruglanski (Eds.), Social psychology: Handbook of basic principles (pp. 702-742). New York: Gilford.

Dick, A. S., \& Basu, K. (1994). Customer loyalty: Toward and integrated conceptual framework. Journal of the Academy of Marketing Science, 22, 99-113.

Ehrenberg, A. S. C., Uncles, M. D., \& Goodhardt, G. J. (2004). Understanding brand performance measures: Using Dirichlet benchmarks. Journal of Business Research, 57, 1307-1325.

Fishbein, M., \& Ajzen, I. (1975). Belief, atitude, intention and behavior: An introduction to theory and research. Reading, MA: Addison-Esley.

Foxall, G.R. (1990/2004). Consumer psychology in behavioural perspective. London and New York: Routledge/Beard Books, Fredericks, MD.

Foxall, G. (1997). Marketing psychology: The paradigm in the wings. London: Macmillan.

Foxall, G. (2002). Consumer behaviour analysis: Critical perspectives. London and New York: Routledge.

Foxall, G. R., Oliveira-Castro, J. M., \& Schrezenmaier, T. C. (2004). The behavioral economics of consumer brand choice: Patterns of reinforcement and utility maximization. Behavioural Processes, 66, 235-260.

Jannarelli, E. (2006). A relação entre o dizer e o fazer para o comportamento de escolha de marcas. Dissertação de Mestrado, Pontifícia Universidade Católica de São Paulo, São Paulo.

Klein, L. R., \& Lansing, J. (1955). Decisions to purchase consumer durable goods. Journal of Marketing, 20(2), 109-132.

Liska, A. E. (1984). A critical examination of the causal structure of the Fishbein/Ajzen attitude-behavior model. Social Psychology Quarterly, 47, 621-674.

Ouelette, J., \& Wood, W. (1998). Habit and intention in everyday life: The multiple processes by which past behaviour predicts future behaviour. Psychological Bulletin, 124, 54-74.

Perillo, R. D. (2007). Avaliando a relação entre satisfação e lealdade dos clientes: Estudo em uma população formada por consumidores de produtos e serviços bancários. Tese de Doutorado. Universidade de Brasília, Brasília.

Petty, R. E. (1995). Attitude change. In A. Tesser (Ed.), Advanced Social Psychology, (vol 6, pp. 195-256). New York: Mcgraw-Hill.

Pieters, R. G., \& Verplanken, B. (1995). Intention-Behavior consistency: Effects of consideration set size, involvement and need for cognition. European Journal of Social Psychology, $25,531-543$.

Pohl, R., \& Oliveira-Castro, J. (2008). Efeitos do nível de beneficio informativo das marcas sobre a duração do comportamento de procura. Revista da Administração Contemporânea Eletrônica, 2(3), 449-469.

Porto, R. (2009). Correspondência dizer-fazer em escolha de marcas: Influência das estratégias de marketing no ponto-devenda e das experiências anteriores dos consumidores. Tese de Doutorado. Universidade de Brasília, Brasília.

Sheeran, P. (2002). The intention-behaviour relations: A conceptual and empirical review. European Review of Social Psychology, $12,1-36$ 
Triandis, H. C. (1980). Values, attitudes and interpesonal behavior. In H. Howe \& M. Page (Eds.), Nebraska symposium on motivation (vol. 27, pp. 159-259). Lincoln, NB: University of Nebraska Press.

Uncles, M., Ehrenberg, A., \& Hammond, K. (1995). Patterns of buyer behavior. Marketing Science, 14, 71-78.

Webb, T. L., \& Sheeran, P. (2006). Does changing behavioral intentions engender behavior change? A meta-analysis of the experimental evidence. Psychological Bulletin, 132, 249-268.
Recebido em 05.10.2010

Primeira decisão editorial em 25.02.2011

Versão final em 01.09.2012

Aceito em 01.11.2012

Psicologia e Saúde Mental

Registro, SP, BR

23 de Fevereiro de 2013 